\title{
Immunomodulatory effects of tick saliva on dermal cells exposed to Borrelia burgdorferi, the agent of Lyme disease
}

Dorothy C. Scholl ${ }^{1,5}$, Monica E. Embers ${ }^{1 *}$, John R. Caskey ${ }^{1}$, Deepak Kaushal ${ }^{1}$, Thomas N. Mather ${ }^{2}$, Wayne R. Buck ${ }^{3,6}$, Lisa A. Morici ${ }^{4}$ and Mario T. Philipp ${ }^{1 *}$

\begin{abstract}
Background: The prolonged feeding process of ixodid ticks, in combination with bacterial transmission, should lead to a robust inflammatory response at the blood-feeding site. Yet, factors present in tick saliva may down-regulate such responses, which may be beneficial to spirochete transmission. The primary goal of this study was to test the hypothesis that tick saliva, in the context of Borrelia burgdorferi, can have widespread effects on the production of immune mediators in skin.
\end{abstract}

Methods: A cross-section of tick feeding on skin was examined histologically. Human THP-1 cells stimulated with B. burgdorferi and grown in the presence or absence of tick saliva were examined by human DNA microarray, cytokine bead array, sandwich ELISA, and qRT-PCR. Similar experiments were also conducted using dermal fibroblasts.

Results: Tick feeding on skin showed dermal infiltration of histiocytes and granulocytes at the bite location. Changes in monocytic transcript levels during co-culture with B. burgdorferi and saliva indicated that tick saliva had a suppressive effect on the expression of certain pro-inflammatory mediators, such as IL-8 (CXCL8) and TLR2, but had a stimulatory effect on specific molecules such as the Interleukin 10 receptor, alpha subunit (IL-10RA), a known mediator of the immunosuppressive signal of IL-10. Stimulated cell culture supernatants were analyzed via antigen-capture ELISA and cytokine bead array for inflammatory mediator production. Treatment of monocytes with saliva significantly reduced the expression of several key mediators including IL-6, IL-8 and TNF-alpha. Tick saliva had an opposite effect on dermal fibroblasts. Rather than inhibiting, saliva enhanced production of pro-inflammatory mediators, including IL-8 and IL-6 from these sentinel skin cells.

Conclusions: The effects of ixodid tick saliva on resident skin cells is cell type-dependent. The response to both tick and pathogen at the site of feeding favors pathogen transmission, but may not be wholly suppressed by tick saliva.

Keywords: Monocyte/Macrophages, Fibroblasts, Lyme disease, Borrelia burgdorferi, Tick saliva, Cytokines, Chemokines, DNA microarray

\section{Background}

Vector-borne infectious diseases such as Lyme borreliosis (LB) result from complex interactions among three major components: host (mammal), pathogen (Borrelia burgdorferi (sensu lato)) and vector (Ixodes spp. ticks). Borrelia burgdorferi, the spirochete that causes LB, is transmitted during the feeding of infected Ixodes ticks.

\footnotetext{
* Correspondence: members@tulane.edu; philipp@tulane.edu ${ }^{1}$ Divisions of Bacteriology and Parasitology, Tulane National Primate Research Center, Covington, LA, USA

Full list of author information is available at the end of the article
}

Borrelia burgdorferi lipoproteins and other pathogenassociated molecular patterns (PAMPs) are involved in the pathogenesis of LB by inducing the production of proinflammatory mediators in cells of the human host [1]. Yet, tick saliva contains several immunomodulatory factors that are thought to play a role in reducing or controlling the inflammatory response [2-4].

Characterizing the immunobiology of the tick-host interface is essential for understanding both tick feeding and pathogen transmission. It is well documented that saliva of blood-feeding arthropods enhances transmission of 
a variety of vector-borne disease-causing agents [5]. The current paradigm suggests that inhibition of host immune defenses via salivary components is a critical element in this process [6-8]. It has also been shown that events at the tick-host interface are so complex that successful transmission of pathogens often depends not only on the immunosuppression of host responses, but also on the enhancement of expression of certain vector genes $[9,10]$. Furthermore, the enhancement of such genes is often mediated by the pathogen as exemplified by the B. burgdorferi-induced expression of two Ixodes scapularis genes, TROSPA (tick receptor for OspA) and Salp15 [9]. Salp 15 has been shown to bind to B. burgdorferi outer surface protein, OspC thereby inhibiting antibody-mediated killing of the pathogen. The establishment of B. burgdorferi infection, therefore, would not be possible without the enhanced expression of Salp15 by the tick.

Several pharmacological properties of tick saliva have been identified and include antihemostatic and vasoactive effects (Maxadilan and other vasodilators, such as the prostaglandin $\mathrm{PGE}_{2}$ ), the inhibition of complement, inactivation of anaphylatoxins and prevention of phagocytosis [2]. Other key immunomodulatory functions of arthropod saliva include inhibition of several cellular activities including nitric oxide production by macrophages [11], natural killer (NK) cell activity, the production of IFN- $\gamma$ [12], histamine-binding capacity [13], and IgGbinding capacity $[2,14,15]$. It has been reported that tick saliva inhibits neutrophil function [16] and interferes with the complement system in vitro $[17,18]$. Additional evidence suggests that chemical components of tick saliva modulate the host cytokine balance and shift cytokine production towards a Th2 response [18-20].

Upon delivery into the host, $B$. burgdorferi does not migrate away from the tick feeding site until several days after the tick has fed to repletion and has detached itself from the host [21, 22]. It is thought that the spirochetes do not migrate because the tick's saliva conditions the host in a way that favors survival of the spirochetes early in infection [9]. Ixodid ticks require several days to feed to repletion. The hypothesis that in order to maintain feeding success, hard ticks require anti-inflammatory and immunosuppressive elements in their saliva has been proposed and supported by several studies [2, 6] We specifically hypothesized that the saliva of the tick interferes with the innate immune response that is elicited by the spirochete in the dermal tissue at the initial site of blood feeding.

The following in vitro experiments were conducted in order to test our hypothesis regarding the effects of tick saliva on dermal cells: (i) the co-culture of activated human monocytes from the THP-1 cell line with $B$. burgdorferi in the presence and absence of tick saliva; and (ii) the co-culture of human or rhesus monkey fibroblasts with $B$. burgdorferi in the presence and absence of tick saliva. Cell culture supernatants from each experiment were used in ELISAs and/or multiplex cytokine bead arrays. RNA extracted from THP-1 monocytes at two time points during co-culture was used in microarray experiments. Validation of microarray results was gained by independent real-time PCR experiments. Here we demonstrate opposing effects of tick saliva on skin-resident cell types.

\section{Methods}

\section{Imaging of tick attachment and feeding}

A $4 \mathrm{~mm}$ biopsy was taken from a rabbit ear posteuthanasia to include the tick and site of feeding. This rabbit was used for saliva collection (partial engorgement of ticks). The biopsy was formalin-fixed, embedded in paraffin and sectioned at $6 \mu \mathrm{m}$. Sections were fixed to slides and stained with hematoxylin and eosin (H\&E).

\section{Monocytes and fibroblasts Monocytes}

This study utilized the human monocytic cell line THP-1 (ATCC TIB-202). Differentiation was induced with Vitamin D-3, 1 $\alpha$, 25-Dihydroxy treatment (Calbiochem, San Diego, CA, USA) at a final concentration of $0.05 \mu \mathrm{M}$ for a maximum of $72 \mathrm{~h}$. This treatment is known to induce the expression of CD14 [23], macrophage morphology, macrophage-specific esterase enzyme activity, and phagocytosis [24]. Cells were seeded at an initial density of $5 \times 10^{5} / \mathrm{ml}$ for pilocarpine control experiments and $2.5 \times 10^{5}$ cells $/ \mathrm{ml}$ for saliva experiments. Cells were stimulated with live B. burgdorferi strain B31-5A19 [25] (MOI 10:1) for $24 \mathrm{~h}$ in the presence or absence of pilocarpine (PC)-induced I. scapularis saliva, where a single dose [26] of $64 \mu \mathrm{g} / \mathrm{ml}$ of total salivary protein was added [27]. Controls included PC-only treated cells, as well as B. burgdorferi + PC- stimulated cells. After stimulation, cell viability was assessed via Trypan Blue staining, and found to be less than $10 \%$ following the addition of saliva. Supernatants were harvested for cytokine bead array, and IL-6, IL-8 and TNF- $\alpha$ detection by antigen-capture ELISA.

\section{Primary rhesus fibroblast purification and culture}

The method for purifying and culturing primary rhesus fibroblasts used in this study was adapted from a previously published protocol used for human fibroblasts [28]. Skin biopsies were taken from animals that were not experimentally infected with pathogens and which were culled from the breeding colony because of chronic diarrhea or injury. The area for the skin biopsy was first shaved and then cleansed with Betadine and ethanol. Upon excision of the sample, it was immediately placed in $40 \mathrm{ml}$ of cold Fibroblast Growth Medium 2 (FGM2, PromoCell, Heidleberg, Germany) and placed on ice. After rinsing with penicillin $(100 \mathrm{UI} / \mathrm{ml})$ and streptomycin 
(100 $\mu \mathrm{g} / \mathrm{ml})$-supplemented sterile phosphate-buffered saline (PBS) (Sigma Chemical Company, St Louis, MO) the dermis was separated from the epidermis. Dermal fragments were then placed onto the scored surface of a sterile Petri dish, covered with FGM2, and allowed to adhere to the dish (approximately one $\mathrm{h}$ ). Once the fragments were attached, $10 \mathrm{ml}$ of FGM2, supplemented with penicillin $(100 \mathrm{UI} / \mathrm{ml})$ and streptomycin $(100 \mu \mathrm{g} / \mathrm{ml})$ and a proprietary supplement mix for FGM2 (PromoCell, Heidelberg, Germany) containing $2 \%$ fetal calf serum, insulin $(5 \mu \mathrm{g} / \mathrm{ml})$ and basic fibroblast growth factor $(1 \mathrm{ng} / \mathrm{ml})$ was added. The dishes were then closed and placed in a $37^{\circ} \mathrm{C}$ incubator, under $5 \% \mathrm{CO}_{2}$. The culture medium was changed every two days in order to maintain an optimal $\mathrm{pH}$ range between 7.6 and 7.8. Fibroblast proliferation occurred in approximately 1-2 weeks. When cultures were approximately $80 \%$ confluent, sub-culturing was done as described [28]. Fibroblasts were passaged three times prior to being used in experiments.

\section{Human fibroblasts}

Normal dermal human fibroblasts were obtained from the American Type Culture Collection (ATCC N ${ }^{\circ}$ PCS201-012). They were grown in PromoCell FGM 2, trypsinizsed with Promocell Trypsin/EDTA and neutralization solution as per the manufacturer's instructions. For experiments, human fibroblasts were plated at $5 \times 10^{4}$ cells/well.

\section{Induction of tick salivation}

Saliva induction involved using a $1.0 \%$ PC in methanol solution applied to the dorsal surface of a partially engorged adult female I. scapularis tick [29]. Collection of salivary secretions was accomplished via glass capillary tubes attached to the hypostome of each tick [30]. Salivary secretions were then pooled and protein concentration was measured using a nanodrop UV spectrophotometer, at $280 \mathrm{~nm}$ absorbance. Saliva was sterile-filtered through a $0.22 \mu \mathrm{m}$ membrane prior to use. Contamination of the saliva with $\mathrm{PC}$ was quantified by high-performance liquid chromatography HPLC, as described later in this section.

\section{Determination of PC concentration in saliva samples by HPLC \\ Sample preparation and standard curve}

Tick saliva $(2-10 \mu \mathrm{l})$ was diluted with $200 \mu \mathrm{l}$ of $10 \mathrm{mM}$ sodium phosphate $\mathrm{pH}$ 7.0, $100 \mu \mathrm{of} 1 \mathrm{mM}$ caffeine (internal standard), and water to a final volume of $400 \mu \mathrm{l}$. The diluted sample was extracted with an equal volume of dichloromethane twice, and the organic phases were pooled and dried under nitrogen. The sample was reconstituted in $200 \mu \mathrm{l}$ mobile phase A (see below), centrifuged briefly at $300 \times \mathrm{g}$, and $20 \mu \mathrm{lwas}$ injected with a
Shimadzu SIL-10ADvp autosampler. Pilocarpine standards were prepared the same way as the samples. The standard concentrations were (in pmol/l) 2880, 1440, 720, 360, 180, 90 and 0 .

\section{Chromatography technique}

Separation was performed using a ShimPack ODS column $(4.6 \times 15 \mathrm{~mm}, 5 \mu \mathrm{m}$ particle size, 100 Angst pore size $)$ at $30{ }^{\circ} \mathrm{C}$. Mobile phase A was composed of $0.6 \%$ triethylamine adjusted to $\mathrm{pH} 2.3$ with phosphoric acid $(85 \% \mathrm{w} / \mathrm{v})$; mobile phase $B$ was methanol. Mobile phases were delivered by paired Shimadzu LC-10ADvp pumps at $1.5 \mathrm{ml} / \mathrm{min}$. Pilocarpine was eluted with mobile phase A for $10 \mathrm{~min}$. Subsequently, caffeine was eluted with a ratio of mobile phases A:B of 7:3 for $10 \mathrm{~min}$. Then the column was equilibrated with mobile phase A for $10 \mathrm{~min}$. Peaks were recorded with a Shimadzu SPD-10ADvp UV/Vis detector, set to $215 \mathrm{~nm}$ for pilocarpine and $275 \mathrm{~nm}$ for caffeine. The retention times for the pilocarpine and caffeine were 7.4 and $16.3 \mathrm{~min}$, respectively.

\section{Data analysis}

Shimadzu EZStart 7.2.1 software was used for data analysis. Pilocarpine peak areas were compared against the internal standard, and logarithmically transformed peak area ratios were quantified against a linear regression standard curve. The concentration of pilocarpine in tick saliva was found to be $2.36 \mathrm{mM}(2.39 \mathrm{pmol} / \mu \mathrm{l})$.

\section{Determination of cytokine/chemokine concentrations by antigen-capture ELISA}

THP-1 monocyte or primary fibroblast supernatants were collected at 12 and $24 \mathrm{~h}$ post-stimulation, aliquoted, and stored at $-80{ }^{\circ} \mathrm{C}$ until used. Controls included supernatants from unstimulated cells. Supernatants were assessed for IL-6, IL- 8 and TNF- $\alpha$ production by ELISA (R\&D Systems) following the manufacturer's instructions. Supernatants were assessed in triplicate and each assay was conducted twice. Statistical significance was determined by two-tailed $t$ test.

\section{Cytokine bead arrays}

THP-1 cell supernatants were collected after 2 and $12 \mathrm{~h}$ of stimulation. Controls included supernatants of unstimulated THP-1 cells. The human cytokine multiplex27 (Luminex xMAP) bead array assay kit was obtained from BioRad Laboratories, Inc. (Hercules, CA) and used according to the manufacturer's instructions. The following mediators were included: IL-1 $\beta$, IL-1ra, IL-2, IL-4, IL-5, IL6, IL-7, IL-8 (CXCL8), IL-9, IL-10, IL-12(p70), IL-13, IL-15, IL-17, Eotaxin, FGF basic, G-CSF, GM-CSF, IFN- $\gamma$, IP-10 (CXCL10), MCP-1 (CCL2), MIP-1 $\alpha$ (CCL3), MIP-1 $\beta$ (CCL4), PDGF-BB, RANTES (CCL5), TNF- $\alpha$, and VEGF. Supernatant samples were run in triplicate and analyzed 
with the Bio-plex 200 Suspension Array System (BioRad). The assay was performed twice. Each analyte concentration was calculated by logistic-5PL regression of the standard curve.

\section{Microarrays}

RNA was isolated from approximately $2.5-5 \times 10^{5}$ cells using the RNeasy kit (Qiagen, Valencia, CA, USA) and rendered free from DNA contamination using the DNAfree reagent (Ambion, Austin, TX). Five hundred ng RNA was amplified and used to synthesize Cy-labelled cDNA with the Amino Allyl Message Amp kit (Ambion, catalog No.1752). Human oligo microarray (44.5 K) chips obtained from the Stanford Functional Genomics Facility (Catalog No.SFGF101) were used for expression analyses in order to determine the levels at which certain genes are expressed with respect to control genes. Cy3 (control) and Cy5 (experimental) -labelled cDNA were mixed in equimolar quantities and hybridized overnight at $55{ }^{\circ} \mathrm{C}$ to SFGF whole-genome microarrays $(4 \times 44.5 \mathrm{~K}$ format), representing approximately 22,000 unique human genes. The slides were scanned on a GenePix 4000B scanner, and data were extracted from the resulting 16-bit TIFF images using GenePix Pro 6.1 software. Data were analyzed using Spotfire DecisionSite for Microarray Analysis. Values were $\log 2$ transformed and normalized using a Locally Weighted ScatterPlot Smoothing (LOWESS) script within S+ ArrayAnalyzer.

Analyses of microarrays were conducted using an approach that focused on specific genes related to immune responses. Within those genes were also a number of genes involved in apoptosis and cell cycle regulatory genes. Microarray data selected for analyses included only those genes that had a $P$-value of $\leq 0.05$ and a change of $\geq 1.5$-fold in both duplicate microarray experiments. Change and log ratio were calculated by combining the two duplicate microarray experiments to produce one value representing change ( $\mathrm{n}$-fold) and one value representing log ratio for each gene. One-way analysis of variance (ANOVA) was performed. An early time point of two hours post-stimulation was evaluated, as was a later time point of $12 \mathrm{~h}$ post-stimulation, in order to assess differences in response to $B$. burgdorferi and $B$. burgdorferi plus tick saliva. Data were analyzed through the use of Ingenuity Pathways Analysis (Ingenuity Systems, www.ingenuity.com) and DAVID Bioinformatics Resources 6.7 (NIAID, NIH). Data sets from each time point and experimental treatment containing gene identifiers and corresponding expression values were uploaded into the application.

Each gene was mapped to its corresponding canonical pathway in Ingenuity's Knowledge Base and with the DAVID database. A fold-change cut-off of 1.5 was set to identify genes whose expression was perturbed at each time point. The significance of the association between the data set and the canonical pathway was measured in two ways: (i) a ratio of the number of molecules from the data set that map to the pathway divided by the total number of molecules that map to the canonical pathway; (ii) Fisher's exact test was used to calculate a $P$-value determining the probability that the association between the genes in the dataset and the canonical pathway is explained by chance alone.

Importantly, the perturbation of gene expression by saliva in the presence of $B$. burgdorferi must take into account the effect of B. burgdorferi alone. For example, if $B$. burgdorferi alone stimulates a 3 -fold increase in expression of gene $\mathrm{X}$, and the value for B. burgdorferi + tick saliva is -1.5 fold, the actual change in expression imparted by tick saliva is -4.5 fold. Therefore, from the 2 and 12-h time points, all genes that were differentially expressed in both groups (B. burgdorferi only and $B$. burgdorferi + saliva) were analyzed by subtracting the expression value of $B$. burgdorferi only from the value of $B$. burgdorferi + saliva. Only those genes that were significantly (1.5-fold or more) affected by both were included in this calculation. In order to further narrow the dataset to function relevant to the transmission of pathogen through the skin, those genes deemed related to immune responses by Ingenuity pathways were categorized into "immune function" or "apoptosis regulation" pathways using the DAVID database.

\section{Real-time PCR}

Relative transcription profiles of IL-10RA and TLR2 were determined by qRT-PCR using the SYBR ${ }^{\circ}$ Green RT-PCR Assay kit (Applied Biosystems, Foster City, CA) with the respective primers specific for each. QuantiTect primers, which are validated, ready-to-use primer sets were obtained from Qiagen for each gene of interest. In addition, transcription of the housekeeping gene GAPDH was determined using specific primers. Real-time PCR reactions were set up in triplicate for each of the cytokines and the housekeeping gene. Amplification conditions were identical for all reactions and consisted of: $2 \mathrm{~min}$ at $50^{\circ} \mathrm{C}$, $10 \mathrm{~min}$ at $95{ }^{\circ} \mathrm{C}, 40$ cycles of $15 \mathrm{~s}$ at $95{ }^{\circ} \mathrm{C}$ and $60 \mathrm{~s}$ at $60{ }^{\circ} \mathrm{C}$. Reaction samples had a final volume of $25 \mu \mathrm{l}$ consisting of $12.5 \mu \mathrm{l}$ of Universal Master mix containing the specific primer/probe mix (Qiagen Quantitect Primer Assays) and $50 \mathrm{ng}$ of the respective RNA template. Amplifications were run in an ABI Prism 7900 Sequence Detection System (Applied Biosystems). Analysis of each run was conducted utilizing the REST program for relative expression, which compares two groups based on PCR efficiencies and the mean crossing point deviation between the sample and the control group. The expression ratio results of the investigated transcripts were tested for significance by a randomization test [31]. 


\section{Results}

\section{Skin damage and inflammation is evident during tick} feeding

While tick saliva is known to suppress multiple mediators of immunity, as outlined in the Background section, it does not shut down inflammation at the site of the tick bite. We obtained a cross-section of an adult Ixodes scapularis tick feeding on a rabbit and stained it with H\&E. Rabbits are known to generate anti-tick immunity following repeated re-infestation [32]. Here, upon primary infestation, recruitment of inflammatory cell types by tick saliva is demonstrated. As shown in Fig. 1, the dermal puncture sight is surrounded by inflammatory cells. The infiltration of cells includes a significant population of histiocytes (derived from monocytes), indicating that the monocyte/macrophage is a relevant cell population for analysis of the impact of tick saliva on the response to $B$. burgdorferi. Also present is a population of granulocytic cells, as previously reported [32]. Thus, pro-inflammatory mediators (e.g. IL-8/CXCL8) that may be induced by exposure of skin fibroblasts to tick saliva should play a role in this response at the site of tick feeding.

\section{Effect of tick saliva on inflammatory mediator production} by THP-1 cells as measured by ELISA

The inflammatory response mediated by nuclear factor$\mathrm{kB}$ pathway (NF-kB) is thought to be a final common

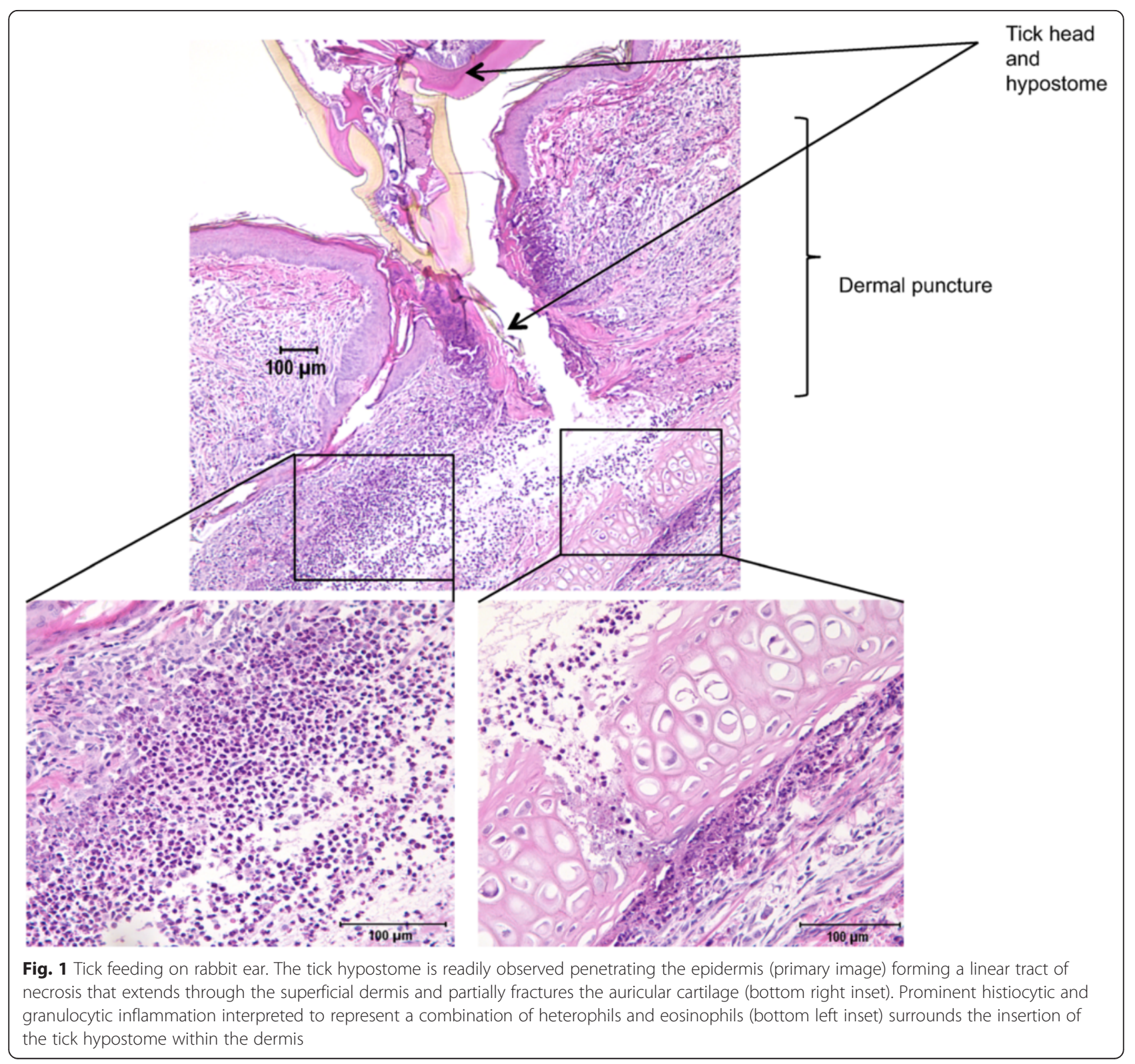


pathway for the translation of a variety of environmental insults, including those caused by blood-feeding arthropods, into inflammation [33]. To evaluate the expression of the pro-inflammatory mediators IL-6, IL-8 (CXCL8) and TNF- $\alpha$ by THP- 1 cells stimulated with $B$. burgdorferi, supernatants were harvested at 12 and $24 \mathrm{~h}$ of incubation for analysis via antigen-capture ELISA. THP-1 cells were co-cultured with $B$. burgdorferi (MOI 10:1) either in the presence or absence of tick saliva $(64 \mu \mathrm{g} / \mathrm{ml}$ protein). Prior experiments demonstrated that saliva had no effect on the production of these mediators by THP1 cells (Additional file 1: Figure S1). At the 24-h (Fig. $2 \mathrm{a}-\mathrm{c}$ ) and 12-h time points (not shown), production of all three pro-inflammatory mediators was significantly inhibited (at least $50 \%, P<0.001$ ) by treatment with saliva. PC added in the concentration range comparable to that found in the saliva pool used in this study induced no inhibition of inflammatory mediator production (Fig. 2a-c). Saliva alone did not elicit inflammatory mediator production (data not shown).

\section{Effect of tick saliva on inflammatory mediator production by THP- 1 cells as measured by cytokine bead array}

The ELISA results showed that tick saliva is able to suppress inflammatory mediator production by THP-1 cells. In order to determine how widespread this effect was, multiplex cytokine bead arrays were used. THP-1 supernatants were collected after 2 and $12 \mathrm{~h}$ of stimulation with B. burgdorferi alone or in addition to either saliva or PC. Culture supernatants of THP-1 cells incubated in medium alone served as the negative control. Supernatant cytokine (analyte) levels were measured for each time point and compared with controls to determine the effect saliva had on the response of monocytes to $B$. burgdorferi (Table 1, Fig. 3). In some instances, the measured analyte was unaffected by saliva treatment (concentrations were comparable to those measured for
THP-1 + B. burgdorferi only) and so these were recorded as "no effect." As with the antigen-capture ELISA experiment, the production of IL-6, IL-8 (CXCL8) and TNF- $\alpha$ elicited by $B$. burgdorferi was significantly inhibited by tick saliva at the 12-h time point, as determined by the cytokine bead array (Table 1). In addition, the production of IL-1 $\beta$, IL-1RA, IL-10, G-CSF, IP-10, MIP- $1 \alpha$, MIP-1 $\beta / C C L 4$, and RANTES also was inhibited after $12 \mathrm{~h}$ of incubation. In contrast, three analytes were enhanced by tick saliva at this time, namely, IL-13, MCP-1, and VEGF. The effect of tick saliva measured at 2-h post-stimulation with $B$. burgdorferi was markedly disparate from that at $12 \mathrm{~h}$. The production of IL-1 $\beta$, IL-6, IL-10, IL-12 (p70), IL-13, and VEGF was significantly enhanced. Indeed, the amount of IL-10 produced almost tripled by treatment with saliva when compared to that produced by THP-1 cells in the presence of $B$. burgdorferi alone (Fig. 4). At $2 \mathrm{~h}$ post-incubation, the following mediators were significantly inhibited: IL-8 (CXCL8), IP10 , MCP-1, MIP- $1 \alpha$, and RANTES, and all but MCP-1 remained inhibited after $12 \mathrm{~h}$.

Importantly, the ability of tick salivary components to bind cytokines [34], chemokines [35] and growth factors [36] could obscure results, especially when the detection relies only on antigen-capture ELISA. We have therefore examined the impact of saliva using cytokine bead array, microarray and examined key pathways using RT-PCR.

\section{Effect of tick saliva on inflammatory mediator production by human and rhesus dermal fibroblasts}

THP-1 cells may be considered as a model for circulating monocytes; these are often found in the dermis. Results from experiments with THP-1 cells indicated that tick saliva might have an inhibitory effect on the production of some pro-inflammatory mediators in skin macrophages, as well as enhance both pro- and anti-inflammatory mediator production in a time-dependent fashion. To evaluate
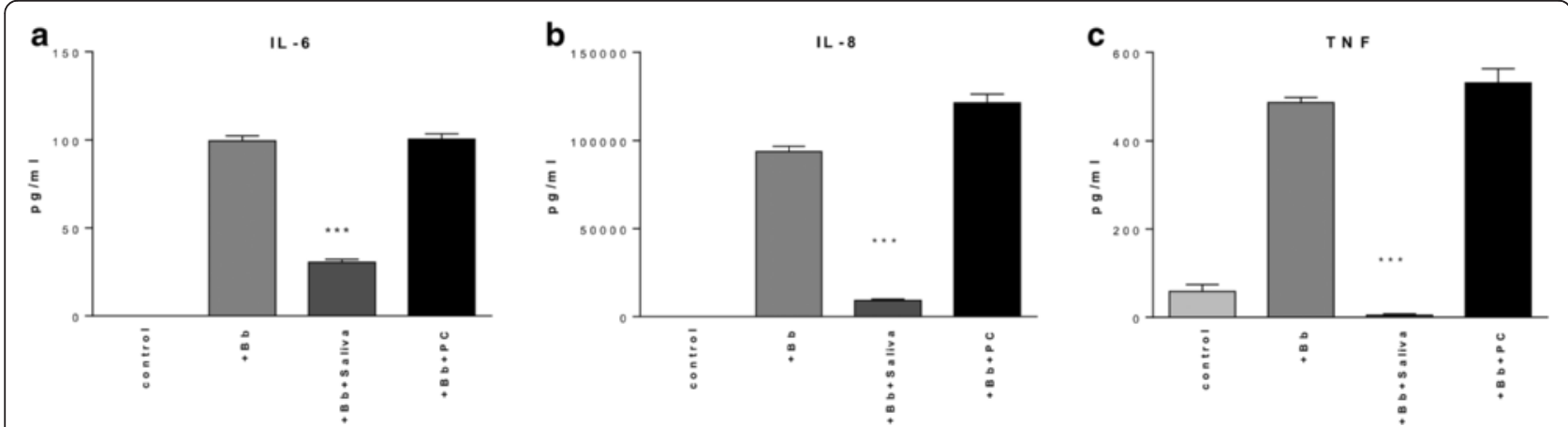

Fig. 2 Effect of tick saliva on inflammatory mediator production by THP-1 cells, as measured by antigen-capture ELISA. Supernatants from THP-1 cells grown for 24 h: unstimulated control (control), incubated with B. burgdorferi (MOI 10:1) (+Bb) alone, B. burgdorferi and 64 Mg saliva (+Bb + Saliva) or $B$. burgdorferi and $0.7 \mu \mathrm{M} \mathrm{PC}(+\mathrm{Bb}+\mathrm{PC})$. Supernatants were subjected to antigen capture ELISA for IL-6 a, IL-8 b and TNF-a c. Cells exposed to B. burgdorferi plus tick saliva showed a significant decrease in inflammatory mediator production. ${ }^{* *} P<0.001$ 
Table 1 Effect of tick saliva on inflammatory mediator (mean \pm standard error) production by THP-1 cells in the presence of B. burgdorferi as measured by cytokine bead array

\begin{tabular}{|c|c|c|c|c|}
\hline \multirow{2}{*}{$\begin{array}{l}\text { 27-plex assay } \\
\text { Mediator }\end{array}$} & \multicolumn{2}{|l|}{$2 \mathrm{~h}$} & \multicolumn{2}{|l|}{$12 \mathrm{~h}$} \\
\hline & $\overline{\mathrm{Bb}}$ & $\mathrm{Bb}+$ saliva & $\overline{\mathrm{Bb}}$ & $\mathrm{Bb}+$ saliva \\
\hline$\overline{I L}-1 \beta$ & $2,793.9 \pm 101.8$ & $3,802.3 \pm 430.3^{\mathrm{a}}$ & $1662.6 \pm 101.1$ & $1,440.8 \pm 12.7^{a}$ \\
\hline IL-1ra & $143.2 \pm 1.3$ & $197.5 \pm 11.0^{\mathrm{a}}$ & $5481.2 \pm 673.3$ & $1,655.5 \pm 28.6^{b}$ \\
\hline IL-6 & $162.8 \pm 5.9$ & $193.4 \pm 21.3$ & $299.9 \pm 11.4$ & $129.2 \pm 4.3^{b}$ \\
\hline IL-8 & $42,586.9 \pm 235.5$ & $24,111.6 \pm 482.3^{b}$ & $170,374.1 \pm 12,978.4$ & $48,064.5 \pm 1,451.6^{b}$ \\
\hline IL-10 & $72.0 \pm 6.8$ & $296.1 \pm 83.8^{b}$ & $553.0 \pm 24.9$ & $251.6 \pm 9.7^{b}$ \\
\hline $\mathrm{IL}-13$ & $94.6 \pm 56.7$ & $202.9 \pm 74.0$ & $289.1 \pm 60.2$ & $541.4 \pm 82.4^{a}$ \\
\hline G-CSF & $109.5 \pm 9.3$ & $63.1 \pm 2.4^{\mathrm{a}}$ & $675.1 \pm 37.3$ & $360.1 \pm 13.3^{b}$ \\
\hline IP-10 & $1,392.6 \pm 94.8$ & $630.2 \pm 48.8^{b}$ & $4,983.9 \pm 1,283.1$ & $4,084.2 \pm 65.5$ \\
\hline MCP-1 & $522.1 \pm 19.0$ & $389.1 \pm 23.9^{\mathrm{a}}$ & $5,190.9 \pm 225.5$ & $6,943.4 \pm 295.6^{a}$ \\
\hline MIP-1a & $21,311.5 \pm 577.8$ & $4,242.5 \pm 300.1^{b}$ & $8,825.5 \pm 550.8$ & $967.2 \pm 53.7^{b}$ \\
\hline RANTES & $5,224.3 \pm 164.1$ & $3,934.6 \pm 129.4^{a}$ & $19,835.9 \pm 521.2$ & $5774.2 \pm 93.5^{b}$ \\
\hline TNF-a & $54,937.7 \pm 3,339.3$ & $5,820.6 \pm 232.5^{b}$ & $2,208.1 \pm 190.0$ & $66.9 \pm 11.7^{b}$ \\
\hline VEGF & $1,470.3 \pm 270.0$ & $4,772.8 \pm 428.4^{b}$ & $19,852.6 \pm 2,237.0$ & $38,831 \cdot 1 \pm 243.0^{b}$ \\
\hline
\end{tabular}

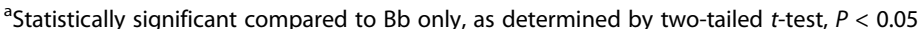

${ }^{\mathrm{b}}$ Statistically significant compared to $\mathrm{Bb}$ only, as determined by two-tailed $t$-test, $P<0.001$

whether these results could be extended to dermal cells of a lineage other than monocytic, we chose to examine primary dermal fibroblasts. Fibroblasts are capable of producing pro-inflammatory mediators, as well as extracellular matrix proteins. They are ubiquitous in the connective tissue of the dermis.

Human dermal fibroblasts were plated as described in Methods. Next, we examined how saliva affected pro-inflammatory mediator production when in the presence and absence of $B$. burgdorferi. Fibroblasts constitutively produced IL- 6 when cultured in medium alone, and incubation with live B. burgdorferi (MOI 10:1) for $24 \mathrm{~h}$ resulted in increased production of this cytokine, as well as that of IL-8/CXCL8 (Fig. 5a, b). Surprisingly, production of both IL-6 and IL-8(CXCL8) by fibroblasts was significantly enhanced when tick saliva was added to

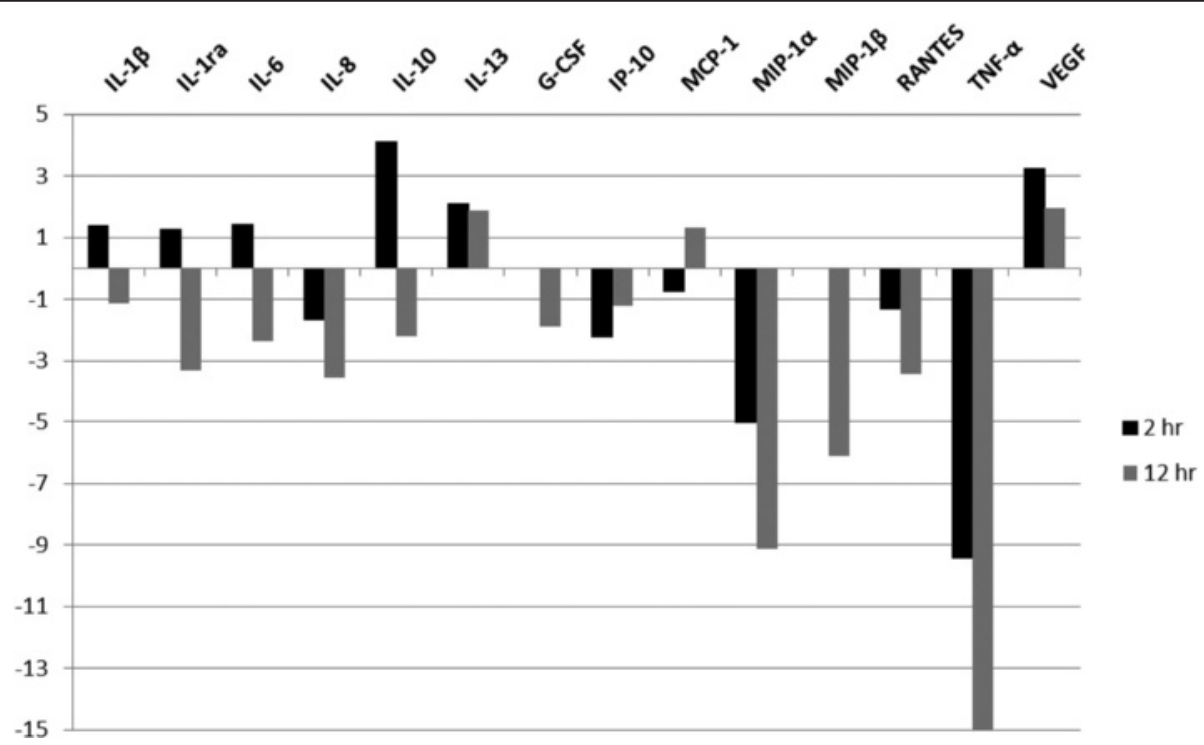

Fig. 3 THP-1 response to tick saliva in the context of B. burgdorferi as measured via cytokine bead array. THP-1 supernatants collected after 2 and $12 \mathrm{~h}$ of stimulation with B. burgdorferi alone or in addition to saliva. The zero (baseline) is the level of stimulation with Bb only and the fold-change indicates that imparted by the addition of saliva. Supernatant analyte levels were measured in $\mathrm{ng} / \mathrm{ml}$ for each time point and compared to determine the effect saliva had on the response of monocytes to B. burgdorferi 


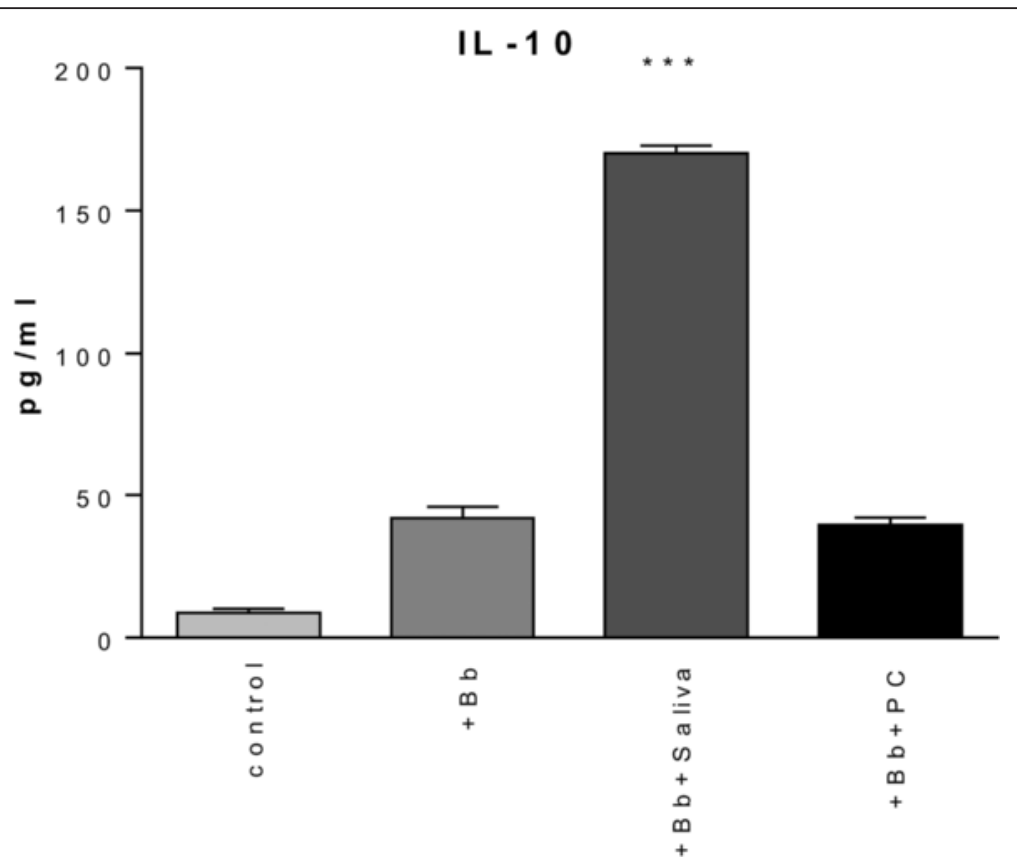

Fig. 4 Effect of tick saliva on IL-10 production by THP-1 cells, as measured by 27-plex cytokine bead array. Supernatants obtained from THP-1 cells after 2-h incubations in medium alone (control), in the presence of B. burgdorferi, MOI 10:1 (+Bb), B. burgdorferi and $64 \mu \mathrm{g}$ tick saliva, (+Bb + Saliva), or $B$. burgdorferi and $0.7 \mu \mathrm{M} P C_{1}(+B b+P C)$, were subjected to cytokine bead array. Cells exposed to $B$. burgdorferi plus tick saliva showed a significant increase in IL-10 production. ${ }^{* *} P<0.001$

the cultures $\left(t\right.$-test: $t_{(5.54)}=-17.909, P<0.0001$ for IL-6 and $t_{(8.66)}=-160.5, P<0.0001$ for IL-8), even in the absence of $B$. burgdorferi $\left(t\right.$-test: $t_{(5.50)}=-14.64, P<0.0001$ for IL- 6 and $t_{(5.40)}=-5.08, P=0.0031$ for IL-8; Fig. 5 a, b). To confirm that this stimulatory effect was not a unique attribute of the batch of tick saliva used in the fibroblast experiment, we re-tested saliva from this batch with THP-1 cells. As before, production of both IL-6 and IL-8(CXCL8) by THP-1 cells was enhanced by exposure to live spirochetes and significantly inhibited by saliva (not shown). The stimulatory effect of saliva on fibroblasts was not unique to human cells, as this phenomenon was also observed with rhesus macaque fibroblasts (not shown). Thus, saliva itself had a pro-inflammatory effect on dermal fibroblasts. This effect was not due to $\mathrm{PC}$, as human fibroblasts incubated with $\mathrm{PC}$ at a concentration commensurate with that present in the saliva specimen had no significant effect on production of IL- 6 or IL-8(CXCL8) by THP-1 cells.

\section{Effect of tick saliva on inflammatory mediator production by THP- 1 cells as measured by DNA microarray}

Results from ELISA and cytokine bead array experiments indicated that saliva has a widespread effect on pro- and anti-inflammatory mediator production by THP-1 cells in the presence of B. burgdorferi. To evaluate the extent of this effect on the expression of not only mediators but also receptors and pathways involved in inflammation, we conducted microarray experiments at two time points: $2 \mathrm{~h}$ and $12 \mathrm{~h}$ post-incubation of THP-1 cells with spirochetes alone, and with spirochetes plus tick saliva. In the analysis of affected genes, two broad categories of gene function dominated the responseimmune function and apoptosis regulation. By restricting the analysis to genes significantly perturbed (1.5-fold or more) in the categories of immune regulation and apoptosis, we were able to characterize the impact of tick saliva on monocytic cells in the context of B. burgdorferi infection. (see Additional file 2: Table S1 and Tables 2 and 3) include lists of all immune function and apoptosis regulatory genes whose expression was affected by $B$. burgdorferi and $B$. burgdorferi plus tick saliva.

In particular, apoptosis facilitators, such as the BCL-2 like genes were upregulated by $B$. burgdorferi, but downregulated by tick saliva (Additional file 2: Table S1c, d and Additional file 3: Table S2c, d). The immune -related genes dominated the responses by monocytic cells to both $B$. burgdorferi and $B$. burgdorferi with saliva (Additional file 2: Table. S1a, b and Additional file 3: Table S2a, b).

\section{2-h time point}

Treatment with B. burgdorferi alone for two hours induced down-regulation of 982 genes and up-regulation of 1015 genes. By $2 \mathrm{~h}$ post-incubation, genes that were 


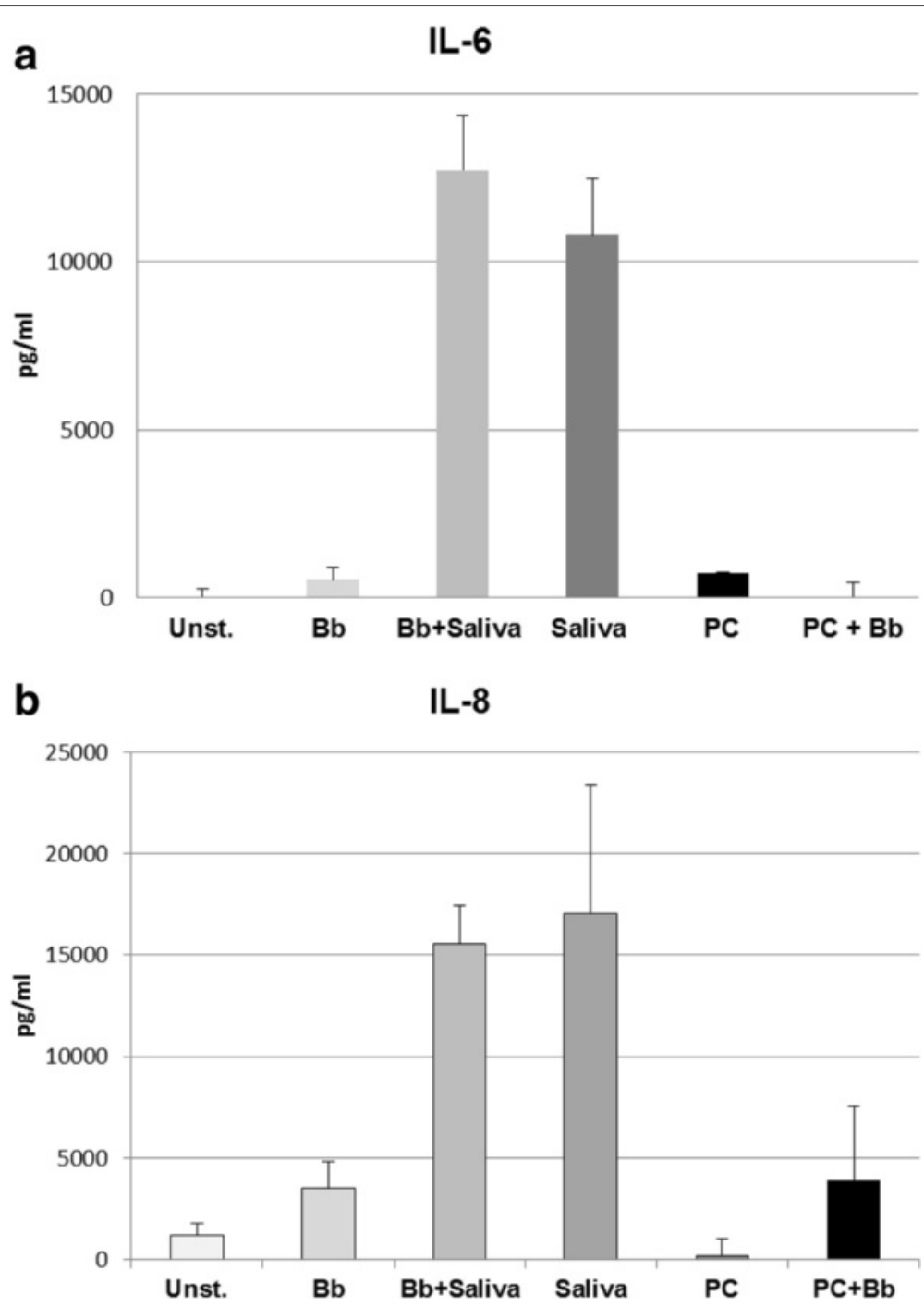

Fig. 5 Effect of tick saliva on inflammatory mediator production by human dermal fibroblasts. Human fibroblasts were plated at $5 \times 10^{5}$ cells per well and cultured for $24 \mathrm{~h}$ in the presence of medium alone (unst), with added live B. burgdorferi 10:1 (Bb), B. burgdorferi + $64 \mu \mathrm{gg}$ saliva (Bb + Saliva), saliva alone (Saliva), $5 \mathrm{mM}$ pilocarpine control (PC), or Bb + PC. The concentrations of IL- $6 \mathbf{a}$ and IL-8 $\mathbf{b}$ were determined by antigen capture ELISA. Cells exposed to $B$. burgdorferi and tick saliva as well as cells exposed only to tick saliva showed a significant increase in inflammatory mediator production; $\mathbf{a} \mid \mathrm{L}-6, P<0.0001$ and $\mathbf{b} \mathrm{IL}-8, P<0.0001$. Each experiment was performed twice, in triplicate. Error bars represent standard deviation between three culture replicates tested in duplicate wells by ELISA

solely up-regulated by B. burgdorferi include the proinflammatory mediators TNF- $\alpha$, IL-6, and IL-8(CXCL8). Borrelia burgdorferi also induced up-regulation of the chemokines MIP-1 $\alpha / C C L 3$ and RANTES/CCL5, both of which attract immune cells to sites of inflammation (Table 3 and Additional file 2, Table S1a, b). TLR2 was not identified as being up-regulated at this particular time point; however, additional experiments in our laboratory have shown that its expression is up-regulated by as early as 30 min post-incubation with $B$. burgdorferi. Specifically, TLR2 was up-regulated 1.6 fold at 30 min by THP-1 cells following co-incubation with $B$. burgdorferi (data not shown). Due to the necessity of
TLR2 for the induction of inflammation by B. burgdorferi [37], and the multiple TLR pathway genes (MYD88, IRAKs, IkBKG, etc.) affected, we elected to examine TLR2 expression closer, with qRT-PCR.

MAP4K4, which encodes a protein kinase and is a member of the serine/threonine protein kinase family was also down-regulated by treatment with $B$. burgdorferi alone by $2 \mathrm{~h}$ post-incubation. (Table 3). MAP4K4 has been shown to activate MAPK8/JNK. However, it has been suggested that this kinase may function through an alternative MAP kinase cascade and mediate the TNF- $\alpha$ signaling pathway. The addition of saliva caused a down-regulation of the expression of TLR2, 
Table 2 Genes related to TLR2 signaling whose expression in THP-1 monocytes was affected by incubation with $B$. burgdorferi and $B$. burgdorferi plus tick saliva at 2 and $12 \mathrm{~h}$ post-incubation

\begin{tabular}{|c|c|c|c|c|}
\hline \multirow[t]{2}{*}{ Gene identifier } & \multicolumn{2}{|l|}{ B. burgdorferi } & \multicolumn{2}{|c|}{ B. burgdorferi + saliva } \\
\hline & $2 \mathrm{~h}$ fold-change & $12 \mathrm{~h}$ & $2 \mathrm{~h}$ fold-change & $12 \mathrm{~h}$ \\
\hline$\overline{C D 14}$ & -1.2 & na & na & na \\
\hline ELK1 & $\mathrm{na}^{\mathrm{a}}$ & -1 & na & na \\
\hline FOS & na & -1.6 & 1.7 & na \\
\hline IKBKG & na & 4 & na & na \\
\hline IRAK1 & 2.6 & -2.2 & na & na \\
\hline IRAK2 & na & 1.1 & na & na \\
\hline$J U N$ & na & 4.9 & na & na \\
\hline MAP2K3 & -1.3 & -2.1 & na & na \\
\hline MAP3K7 & na & 5.0 & na & na \\
\hline MAP3K7I & -2 & na & na & na \\
\hline MAP4K4 & -3.3 & 4.9 & 1.3 & na \\
\hline MAPK8 & -1.5 & na & na & na \\
\hline MAPK12 & -1.1 & na & na & na \\
\hline MAPK13 & -1.1 & na & na & na \\
\hline MAPK14 & -4.2 & 3.6 & na & 1.3 \\
\hline MYD88 & na & 1.5 & na & na \\
\hline TIRAP & -1.0 & 4.1 & na & na \\
\hline TLR1 & na & 2.6 & na & na \\
\hline TLR2 & na & na & -1.7 & na \\
\hline TLR7 & na & -4.9 & na & na \\
\hline TLR8 & na & 1.6 & na & na \\
\hline TLR9 & na & 3.2 & na & na \\
\hline TOLLIP & na & 5.4 & na & na \\
\hline
\end{tabular}

${ }^{a}$ na, no data were generated for this gene identifier at this particular time point under those experimental conditions

TNF- $\alpha$, MIP- $1 \alpha C C L 3$, IL-17, and MIP-1 $\beta /$ CCL4 by $2 \mathrm{~h}$ post-incubation (Table 2 and Additional file 2, Table S1b). Tick saliva contains copious amounts of eicosanoids in the form of prostaglandins. Prostaglandins have both pro-inflammatory functions, including vasodilatory and fever-inducing, as well as immune modulatory functions such as inhibiting TNF- $\alpha$, IL-1 $\beta$ and IL-12. Prostaglandins can also stimulate the production of IL-10 and therefore indirectly inhibit many aspects of cell-mediated immunity [38].

By $2 \mathrm{~h}$ post-incubation with $B$. burgdorferi and saliva, a total of only 803 genes were down-regulated, while 1103 genes were up-regulated. At this early time point, treatment with saliva caused an up-regulation of the expression of SOCS3, as well as MAP4K4. Conversely, saliva treatment at this time point had an inhibitory effect on the expression of CCR1, a receptor for several pro-inflammatory chemokines, including $\mathrm{MIP}-1 \alpha$, and RANTES.
Table 3 Microarray analysis of genes related to the IL-10 pathway whose expression in THP-1 monocytes was affected by incubation with B. burgdorferi and tick saliva at 2 and $12 \mathrm{~h}$ post-incubation

\begin{tabular}{|c|c|c|c|c|}
\hline \multirow[t]{2}{*}{ Gene identifier } & \multicolumn{2}{|c|}{ B. burgdorferi } & \multicolumn{2}{|c|}{ B. burgdorferi + saliva } \\
\hline & $2 \mathrm{~h}$ & $12 \mathrm{~h}$ fold-change & $2 \mathrm{~h}$ & $12 \mathrm{~h}$ \\
\hline $\mathrm{BCL} 3$ & 2.2 & na & 1.3 & na \\
\hline BLVRE & $n a^{a}$ & -2.6 & na & na \\
\hline CCR1 & na & na & -1.1 & na \\
\hline CD14 & -1.2 & na & na & na \\
\hline ELK1 & na & -1.0 & na & na \\
\hline FCGR2A & na & -1.9 & na & na \\
\hline FCGR2B & na & -1.3 & na & na \\
\hline FCGR2C & na & -1.7 & na & na \\
\hline FOS & na & -1.6 & na & na \\
\hline HMOX1 & na & 2.0 & na & na \\
\hline IKBKG & na & 4.0 & na & na \\
\hline IL10RA & -1.8 & na & na & na \\
\hline IL10RB & na & -1.1 & na & na \\
\hline $\mathrm{IL} 1 \mathrm{~B}$ & 3.3 & 2.7 & na & na \\
\hline IL1F5 & -2.3 & na & na & na \\
\hline IL1F9 & na & 5.1 & na & na \\
\hline IL1F10 & 6.7 & na & na & na \\
\hline |L1R1 & na & na & na & -1.3 \\
\hline JUN & na & 4.9 & na & na \\
\hline MAP2K3 & -1.3 & -2.1 & na & na \\
\hline MAP3K7 & na & 5.0 & na & na \\
\hline MAP3KK7I & -2.0 & na & na & na \\
\hline MAP4K4 & -3.2 & 4.9 & 1.3 & na \\
\hline MAPK8 & -1.5 & na & na & na \\
\hline MAPK12 & -1.1 & -2.9 & na & na \\
\hline MAPK13 & -1.1 & na & na & na \\
\hline MAPK14 & -4.2 & 3.6 & na & 1.3 \\
\hline SOCS3 & na & 5.8 & 1.4 & na \\
\hline STAT3 & na & -1.0 & na & na \\
\hline SP1 & -1.6 & na & na & na \\
\hline TNF-a & na & 4.5 & na & na \\
\hline TYK2 & na & -1.9 & na & na \\
\hline
\end{tabular}

${ }^{a}$ na, no data were generated for this gene identifier at this particular time point under those experimental conditions

\section{2-h time point}

A total of 7918 genes were down-regulated and 3866 genes were up-regulated after $12 \mathrm{~h}$ of incubation of THP-1 monocytes with $B$. burgdorferi alone. The addition of saliva and $B$. burgdorferi for the same time period caused the up-regulation of 1203 genes and the down-regulation of 1371 genes. By $12 \mathrm{~h}$ post-incubation, among the genes that were affected by treatment with $B$. 
burgdorferi alone were the pro-inflammatory mediators IL-1 $\beta$ and TNF- $\alpha$, which were up-regulated. By this time point, the expression of MAP4K4, a potential mediator of TNF- $\alpha$ signaling, was also up-regulated by nearly 5 fold. Down-regulated genes from this sample included TLR-7, MHC genes, complement-related genes and IL-17 receptors (Additional file 3, Table S2b). Some of the genes up-regulated in the saliva-treated samples included TNF$\alpha$ and IL10RA (Table 2, Additional file 3, Table S2a). Down-regulated genes in the same sample included IL-13, IL-19, and TGF $\beta$.

Those genes affected by treatment with both spirochetes alone, and with treatment including spirochetes plus tick saliva are shown in Tables 2 and 3, and Additional files 2 and 3 . With respect to genes affected by $B$. burgdorferi, and also modulated by tick saliva (Tables 4, 5, 6 and 7), several genes involved in the innate response, especially at $2 \mathrm{~h}$ are down-regulated (Table 4). Most notably, CCL4 (also known as macrophage inflammatory protein $1 \beta$ ) and CCL4L2 are significantly down-regulated by saliva. This may help shut down recruitment of macrophages and NK cells to the site of tick feeding. The down-regulation of TGF $\beta$ and HLA may also serve to reduce inflammation and

Table 4 B. burgdorferi-perturbed genes down-regulated after $2 \mathrm{~h}$ of stimulation

\begin{tabular}{|c|c|c|}
\hline Gene & Relative expression & Description \\
\hline MMP23B & -0.1740859 & $\begin{array}{l}\text { Matrix metallopeptidase 23A } \\
\text { (pseudogene); matrix } \\
\text { metallopeptidase 23B }\end{array}$ \\
\hline CCL4 & -5.833905 & Chemokine ( $\mathrm{C}-\mathrm{C}$ motif) ligand 4 \\
\hline CD209 & -0.6862013 & CD209 molecule \\
\hline AlFM1 & -0.4024457 & $\begin{array}{l}\text { Apoptosis-inducing factor, } \\
\text { mitochondrion-associated, } 1\end{array}$ \\
\hline KIR3DL1 & -0.6602146 & Killer cell immunoglobulin-like receptor \\
\hline $\mathrm{ITIH} 5$ & -0.2748285 & Inter-alpha (globulin) inhibitor H5 \\
\hline IL6R & -0.0037182 & Interleukin 6 receptor \\
\hline MAPK8IP1 & -0.2555757 & $\begin{array}{l}\text { Mitogen-activated protein kinase } 8 \\
\text { interacting protein } 1\end{array}$ \\
\hline MAPK8IP2 & -0.361055 & $\begin{array}{l}\text { Mitogen-activated protein kinase } 8 \\
\text { interacting protein } 2\end{array}$ \\
\hline CCL4L2 & -3.7781608 & $\begin{array}{l}\text { Chemokine (C-C motif) ligand 4-like } \\
\text { 1; chemokine ( } \mathrm{C}-\mathrm{C} \text { motif) ligand } \\
\text { 4-like } 2\end{array}$ \\
\hline MAP4K4 & -0.151645 & $\begin{array}{l}\text { Mitogen-activated protein kinase } \\
\text { kinase kinase kinase } 4\end{array}$ \\
\hline GPR56 & -0.0379491 & G protein-coupled receptor 56 \\
\hline BCL2L14 & -1.0708373 & BCL2-like 14 (apoptosis facilitator) \\
\hline LTBP4 & -0.3332754 & $\begin{array}{l}\text { Latent transforming growth factor } \\
\text { beta binding protein } 4\end{array}$ \\
\hline TRAF4 & -0.4525453 & TNF receptor-associated factor 4 \\
\hline IL17RC & -0.4447441 & Interleukin 17 receptor $\mathrm{C}$ \\
\hline
\end{tabular}

dampen the onset of adaptive immunity. Genes that promote apoptosis (AIFM1, BCL2L14, CARD15) appear also to be down-regulated by tick saliva at 2 and $12 \mathrm{~h}$ (Table 4, 5 and 6); however, the pro-apoptotic gene BAX is up-regulated at $12 \mathrm{~h}$ (Table 7). Appropriately, cell signaling molecules such as the mitogen-activated protein kinases and NFkB genes are also perturbed with B. burgdorferi and tick saliva.

\section{Real-time reverse-transcriptase PCR}

To verify the results of the microarray experiments, we conducted quantitative real-time reverse transcriptase PCR on two genes of interest, TLR2 and IL-10RA (Fig. 6 a, b). RNA harvested after $2 \mathrm{~h}$ of incubation was used as template. TLR2 expression was significantly diminished in those samples obtained from $B$. burgdorferi plus saliva treatment when compared to RNA obtained from samples not receiving any saliva treatment. RNA obtained after $12 \mathrm{~h}$ of incubation was used for the qRT-PCR analysis of IL-10RA expression. Relative expression of $I L-10 R A$ was significantly elevated in RNA samples obtained from the B. burgdorferi + saliva treatment compared to no saliva treatment. These data confirm the validity of microarray data.

\section{Discussion}

The goal of this study was to examine the effect of tick saliva on monocytes and primary dermal fibroblasts when these cells were exposed to B. burgdorferi. These two cell types are both found in the skin, where the first point of contact between the vector, pathogen, and host is located. In these studies, we utilized a human cell line (THP-1) for the monocyte model, and primary cells for the fibroblast model. While a pure population of human primary monocyte/macrophages may have yielded more relevant findings, our cytokine results are in agreement with published data [39] and expand upon available information regarding gene expression. The surface of the skin is constantly exposed to potential pathogens, yet wide-ranging skin infections are relatively rare, owing to efficacy of the immune response by the skin [40]. Supporting this notion is the demonstration that dermal fibroblasts are capable of secreting several immunomodulators, including IFN- $\gamma, \mathrm{PGE}_{2}$, IL-1, IL-6, and IL-8 (CXCL8) while monocytes and macrophages present in the skin play roles in immune defense, inflammation and tissue remodelling [41]. Along with monocyte/macrophages, Langerhans cells and dermal dendritic cells (DCs) serve as the antigen-presenting cells (APC) which act as key regulators bridging the innate and adaptive responses. These cells pick up antigen [42] and migrate to the regional lymph nodes, where they present antigen to effector $\mathrm{T}$ cells. Among the demonstrated effects of Ixodes tick saliva on dendritic cells (reviewed in [43]) are 
Table 5 B. burgdorferi-perturbed genes up-regulated after $2 \mathrm{~h}$ of stimulation

\begin{tabular}{|c|c|c|}
\hline Gene & Relative expression & Description \\
\hline IGHGI & 0.07896333 & $\begin{array}{l}\text { Variable 3-11 (gene/pseudogene); immunoglobulin heavy variable 4-31; immunoglobulin } \\
\text { heavy locus }\end{array}$ \\
\hline HIF1AN & 1.40558447 & Hypoxia inducible factor 1, alpha subunit inhibitor \\
\hline FGFR3 & 3.37091511 & Fibroblast growth factor receptor 3 \\
\hline CD6 & 2.9080693 & CD6 molecule \\
\hline CD300E & 0.65831278 & CD300e molecule \\
\hline CD200 & 2.10422558 & CD200 molecule \\
\hline GPR89A & 1.7942643 & G protein-coupled receptor \\
\hline BAT3 & 0.09701591 & HLA-B associated transcript 3 \\
\hline IL15RA & 0.28488171 & Interleukin 15 receptor, alpha \\
\hline NCF1 & 0.41282425 & Neutrophil cytosolic factor 1 \\
\hline MAP3K7IP1 & 0.13999618 & Mitogen-activated protein kinase kinase kinase 7 interacting protein 1 \\
\hline RAB1A & 0.68755658 & RAB1A, member RAS oncogene family \\
\hline IL12RB1 & 0.78907124 & Interleukin 12 receptor, beta 1 \\
\hline TNFRSF13B & 0.02283238 & Tumor necrosis factor receptor superfamily, member 13B \\
\hline IL1F10 & 1.59882878 & Interleukin 1 family, member 10 (theta) \\
\hline BAD & 0.44343992 & BCL2-associated agonist of cell death \\
\hline RASSF7 & 1.95038068 & Ras association (RalGDS/AF-6) domain family (N-terminal) member 7 \\
\hline RASGRF1 & 0.28493451 & Ras protein-specific guanine nucleotide-releasing factor 1 \\
\hline CNOT7 & 0.31888622 & CCR4-NOT transcription complex, subunit 7 \\
\hline LTBP1 & 2.24423737 & Latent transforming growth factor beta binding protein 1 \\
\hline CD44 & 0.61183676 & CD44 molecule (Indian blood group) \\
\hline
\end{tabular}

inhibition of phagocytosis [44], suppression of inflammatory signals $[44,45]$ and interference with antigen presentation [46, 47].

In addition, recent studies have shown that coincubation of keratinocytes and dermal fibroblasts with $B$. burgdorferi induce an inflammatory response [48, 49]. Mediators such as IL-8 (CXCL8) and the antimicrobial peptides human $\beta$-defensin- 2 and cathelicidin LL-37 were induced upon co-incubation with $B$. burgdorferi by both keratinocytes and fibroblasts $[48,49]$. Our results are in agreement with these

Table 6 B. burgdorferi-perturbed genes down-regulated after $12 \mathrm{~h}$ of stimulation

\begin{tabular}{|c|c|c|}
\hline Gene & Relative expression & Description \\
\hline $\mathrm{BCL} 7 \mathrm{~B}$ & -0.00593926 & B-cell CLL/lymphoma 7B \\
\hline CARD15 & -2.990009101 & $\begin{array}{l}\text { Caspase recruitment domain family, } \\
\text { member } 15\end{array}$ \\
\hline $\begin{array}{l}\text { HLA- } \\
\text { DMB }\end{array}$ & -7.115679019 & $\begin{array}{l}\text { Major histocompatibility complex, class II, } \\
\text { DM beta }\end{array}$ \\
\hline RAB4B & -6.491 & RAB4B, member RAS oncogene family \\
\hline RASSF7 & -4.73653 & $\begin{array}{l}\text { Ras association (RalGDS/AF-6) domain } \\
\text { family (N-terminal) member } 7\end{array}$ \\
\hline TGFB1 & -4.967537664 & Transforming growth factor, beta 1 \\
\hline
\end{tabular}

studies, but are expanded to include the effect of saliva. In a subsequent study, Marchal et al. [4] showed that tick salivary gland extract has an inhibitory effect on the expression of inflammatory mediators in keratinocytes when co-incubated with $B$. burgdorferi. These results support the current paradigm that molecules present in tick saliva have the capacity to inhibit many host immune functions [7]. As regulators of inflammation, monocytes are able to produce pro-inflammatory mediators such as IL-8 (CXCL8), a chemokine that controls the influx of

Table 7 B. burgdorferi-perturbed genes up-regulated after $12 \mathrm{~h}$ of stimulation

\begin{tabular}{|c|c|c|}
\hline Gene & Relative expression & Description \\
\hline BAX & 3.864113319 & BCL2-associated $X$ protein \\
\hline CD79B & 4.848595465 & $\begin{array}{l}\text { CD79b molecule, immunoglobulin- } \\
\text { associated beta }\end{array}$ \\
\hline MMP25 & 3.984962116 & Matrix metallopeptidase 25 \\
\hline NFKB2 & 1.78061484 & $\begin{array}{l}\text { Nuclear factor of kappa light polypeptide } \\
\text { gene enhancer in B-cells } 2 \text { (p49/p100) }\end{array}$ \\
\hline NFKBIL1 & 2.477201984 & $\begin{array}{l}\text { Nuclear factor of kappa light polypeptide } \\
\text { gene enhancer in B-cells inhibitor-like } 1\end{array}$ \\
\hline RASGRF1 & 2.626291514 & $\begin{array}{l}\text { Ras protein-specific guanine nucleotide- } \\
\text { releasing factor } 1\end{array}$ \\
\hline
\end{tabular}




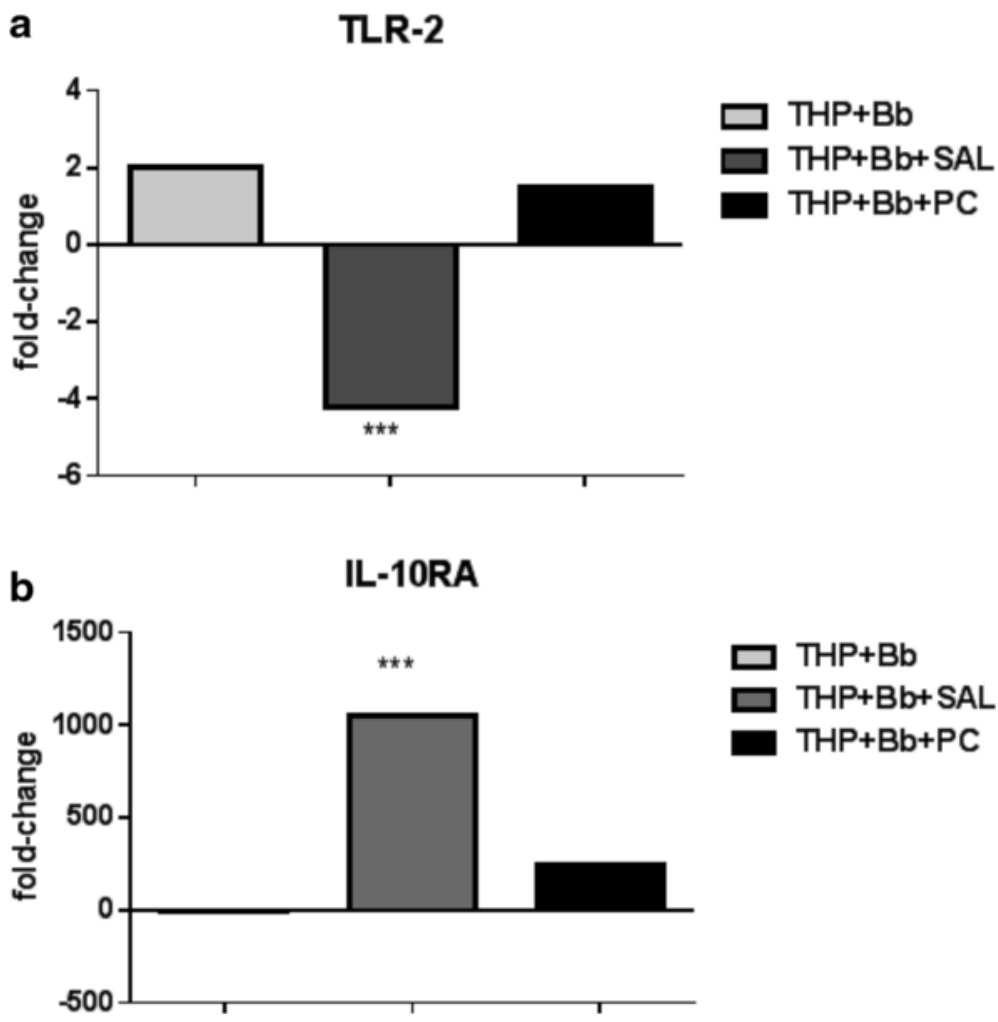

Fig. 6 TLR2 and IL-1ORA qRT-PCR results THP-1 RNA was extracted from 2-h cultures stimulated with B. burgdorferi (1:10) alone, B. burgdorferi and saliva or B. burgdorferi and $0.7 \mu \mathrm{M}$ PC. Real-time PCR was performed for TLR2 and IL-10RA relative expression levels. $\mathbf{a}$, Transcript levels from cells exposed to B. burgdorferi and saliva showed a significant decrease in TLR2 expression at $2 \mathrm{~h}$ post-stimulation (*** $P=0.001$ ); $\mathbf{b}$, Transcript levels from cells exposed to $B$. burgdorferi and saliva showed a significant increase in IL-10RA expression $\left({ }^{* *} P=0.015\right)$

inflammatory and immune cells to sites of injury and infection, and IL-6, a key B cell differentiation factor.

A fundamental element in the host's innate immune response is inflammation. Inflammation causes increased vascular permeability, which promotes the migration and influx of immune cells to areas of tissue damage. The current paradigm, widely described in the literature, suggests that, in order to maintain feeding, hard ticks require anti-inflammatory mediators in their saliva so that they may feed to repletion and remain relatively undetected by their host. In addition to several pharmacologically active compounds, saliva does contain antiinflammatory agents. Hard ticks must remain attached to their host for several days without initiating a wound healing response at the site of dermal tissue damage. Our initial goal was to test the hypothesis that tick saliva would have global suppressive or inhibitory effects on the production/transcription of pro-inflammatory mediators secreted by dermal cells such as blood monocytes and fibroblasts. However, our results suggest that the current paradigm may be an oversimplification of a more complex interplay between host, vector and pathogen. Tick saliva was able not only to inhibit but also enhance inflammatory mediator production and transcription elicited by B. burgdorferi in monocytes. In fibroblasts, it was able to elicit production of pro-inflammatory mediators even in the absence of the spirochete. While a previous study indicated that tick saliva can have a cytotoxic effect on fibroblasts [49], or slow cell proliferation [36] we did not observe decreased viability and our study was too short to measure the impact on proliferation. The discrepancy in cytotoxicity could be due to differences in methodology, with our use of saliva versus salivary gland extract. Moreover, saliva effects on monocytes in some cases depended on the length of exposure to the saliva, and could switch from early inhibitory to late enhancing, and vice versa.

If we inspect the area of tick feeding histologically (Fig. 1), the dermal puncture site is not free of inflammatory cells. Indeed, inflammatory cells are recruited to the abrasion site of the dermis and even below the basement membrane. The wound-healing response is not globally down-regulated by tick saliva, but is limited to the dermis. Relatively little inflammation is seen in the epidermis at the site of feeding.

It has previously been demonstrated that salivary gland extracts (SGE) from $I$. ricinus inhibits production of IFN- $\gamma$ through the up-regulation of IL-10 [50]. 
Furthermore, studies utilizing $\mathrm{C} 3 \mathrm{H} / \mathrm{HeN}$ mice demonstrated the effects of infestation with $I$. scapularis nymphs on chemokine production. Repeated infestations with pathogen-free I. scapularis nymphs decreased the production of macrophage-derived chemokines such as IL- $1 \beta$, IL- 6 and TNF- $\alpha$ and increased the production of T lymphocyte cytokines such as IL-2, IL-4, and IL-10 in $\mathrm{C} 3 \mathrm{H} / \mathrm{HeN}$ mice [51]. Our experiments with $I$. scapularis saliva, live B. burgdorferi, and THP-1 monocytes (ELISAs, multiplex cytokine bead array, microarray and qRT-PCR) yielded data that support these earlier findings as well as our initial hypothesis. Certain components in saliva suppress or inhibit the expression of pro-inflammatory mediators by these monocytes. THP-1 monocytes treated with tick saliva in the presence of live $B$. burgdorferi demonstrate that saliva inhibits several pro-inflammatory mediators, including IL-6, IL-8 (CXCL8), and TNF- $\alpha$. Furthermore, treatment with saliva enhances the expression of several anti-inflammatory mediators by THP-1 monocytes, including, IL-10, IL-10RA, and IL-13, which can down-regulate macrophage activity, and inhibit the production of pro-inflammatory cytokines and chemokines. It has also been previously demonstrated that interleukin-10 (IL-10), produced by THP-1 monocytes in response to $B$. burgdorferi, inhibits the production of concomitantly elicited inflammatory cytokines [52]. Thus, IL-10 could potentially down-regulate inflammatory and microbicidal effector mechanisms of the innate immune response to a $B$. burgdorferi infection, facilitating the establishment of the spirochete. Also consistent with the effect of B. burgdorferi [53] and tick saliva [54] on vascular permeability is the upregulation of VEGF production by both, as shown in Table 1.

TLR2 is a key receptor involved in recognition of $B$. burgdorferi by monocytes/macrophages. Our THP-1 monocyte microarray results demonstrate that tick saliva in the presence of B. burgdorferi suppresses TLR2 expression in monocytes by as early as $2 \mathrm{~h}$ poststimulation (Table 2 and Additional file 2, Table S1b). This may represent one of the earliest points of interference by the tick on the host's innate immune response. Similar results have also been obtained using dendritic cells [55]. TLR2 inhibition has downstream effects on the ability of monocytes to produce several pro-inflammatory mediators. PAMP recognition by TLRs initiates various innate immune responses including phagocytosis, production of antimicrobial compounds and inflammatory mediators, which in turn induce the killing of microorganisms and initiate the acquired immune response. Microbial infection such as that caused by $B$. burgdorferi involving skin damage through injury (tick feeding) leads to the activation of the inflammatory response by activation of several cellular signalling pathways, including the NF-kB via TLR2. NF-KB-mediated gene transcription can induce the expression of primary cytokine and chemokine production in monocytes/macrophages, fibroblasts, and other resident skin cells [56].

Addition of B. burgdorferi perturbed several genes, including SOCS3, SOCS4 and SOCS5, which were upregulated (see Additional file 2, Table S1a; Additional file 3: Table S2a) and play a role in suppressing cytokine and chemokine signalling by binding to and inhibiting JAK2 kinase. When saliva was added, SOCS3 remained upregulated (1.28-fold) at the 2-h time point (data not shown), thus indicating that saliva does not curb this mode of immunosuppression. SOCS3 is involved in negative regulation of cytokines that signal through the JAK/ STAT pathway [57], whereas SOCS4 and 5 appear to regulate the epidermal growth factor receptor [58], also seen down-regulated at $12 \mathrm{~h}$. By $12 \mathrm{~h}$ post-incubation with $B$. burgdorferi and saliva, THP-1 expression of the heterodimeric receptor for IL-10, IL10RA, was increased by over 2 -fold. This upregulation is significant because of the role that IL10RA plays in IL-10-Stat3 signalling. IL-10 binds to IL-10RA which then activates Jak1 and Tyk2 followed by Stat3 phosphorylation [59]. Stat3 is at least partially required for the inhibitory functions of IL10 and induces the expression of SOCS3 which regulates a variety of cytokine signalling pathways, including IL-6 [59]. Indeed, the expression of SOCS genes is induced by various cytokines, including IL-6, IL-10, and IFN- $\gamma$. The observation that B. burgdorferi stimulates an increase in the expression of SOCS3 is therefore not unexpected.

A prominent response was the downregulation of CCL4 and CCL4L2 (ligand) by tick saliva. The decrease in expression of CCL4 was nearly 6 -fold (Table 4) from that induced by B. burgdorferi alone. MIP-1 proteins mediate their effects by binding to cell surface CC chemokine receptors, which belong to the G-protein-coupled receptor superfamily. The high affinity interactions of receptor binding induce a subsequent cascade of intracellular events that rapidly leads to a wide range of target cell functions including chemotaxis, degranulation, phagocytosis, and mediator synthesis [60]. This reduction in the amount of chemoattractive inflammatory mediator may thus be a key element to saliva-aided pathogen survival in the skin during transmission.

In summary, microarray and qRT-PCR experiments using THP-1 monocytes co-cultured with B. burgdorferi and saliva demonstrate inhibition of TLR2 expression. Furthermore, we showed that saliva stimulates IL-10 production by $2 \mathrm{~h}$ of co-incubation, and IL-10RA expression is up-regulated by $12 \mathrm{~h}$ of co-incubation. IL-10 both down-regulates expression of Th1 type cytokines, and blocks NF-kappa B activity, while IL-10RA mediates the immunosuppressive effects of IL-10.

Experiments with human and rhesus primary dermal fibroblasts yielded results which do not support our 
initial hypothesis. ELISAs conducted with supernatants obtained from fibroblasts co-cultured with $B$. burgdorferi and saliva demonstrated that saliva elicits pro-inflammatory mediator production by these cells. Saliva does not inhibit IL-6, nor does it inhibit IL-8 (CXCL8), but rather, it significantly enhances production of both mediators. These results demonstrate that saliva has the opposite effect on primary dermal fibroblasts compared to its effect on THP-1 monocytes. Even in the absence of pathogen, tick saliva stimulates the expression of certain pro-inflammatory mediators by these cells. Fibroblasts secrete proinflammatory mediators, yet inflammation may be averted due to the counter measures imparted by the tick's saliva on cells of the innate immune system, typified by monocytes/macrophages. Furthermore, recent research has suggested that anti-inflammatory agents present in tick saliva are capable of suppressing the release of local growth factors such as PDGF, EGF and TGF $\alpha$, which play critical roles in the recruitment of fibroblasts into the site of tissue damage [18]. Studies conducted by Kramer et al. [61] demonstrate that SGE from Dermacentor variabilis suppresses the ability of fibroblasts to repair injury. Additional experiments show that SGE and saliva can inhibit fibroblast migration and reduce ERK activity [61].

The issue of timing may be a factor in the prevention of inflammation. Tick saliva may stimulate the production of inflammatory mediators by fibroblasts at the site of feeding early on, recruiting monocytes/macrophages to the site. However, the inhibition of monocytic responses at this point may prevent further inflammation and recruitment and/or stimulation of the cells of the adaptive immune response from the regional lymph nodes.

\section{Conclusions}

Our results indicate that saliva can both suppress and stimulate the expression of pro-inflammatory mediators such as IL-6 and IL-8(CXCL8), depending on the cell type, and suggest that fibroblasts may be involved in immune responses that the tick is ultimately able to evade. The main conclusions that may be drawn from this study include the following: (i) saliva, while able to inhibit key pro-inflammatory pathways, is not a universal inhibitor of inflammation; and (ii) the effects of saliva in this regard are crucially dependent on the length of interaction with host cells, and on the type of host cell involved.

\section{Additional files}

Additional file 1: Figure S1. Comparison of THP-1 responses to $B$. burgdorferi and saliva. Levels of IL-6 (top panel) and IL-8 (bottom panel) were compared when THP-1 cells were incubated with $B$. burgdorferi and 2 different dilutions of saliva (1:20 and 1:500). (TIF $379 \mathrm{~kb}$ )
Additional file 2: Table S1. Genes perturbed at $2 \mathrm{~h}$ post-stimulation. (DOCX $41 \mathrm{~kb}$ )

Additional file 3: Table S2. Genes perturbed at $12 \mathrm{~h}$ post-stimulation. (DOCX $43 \mathrm{~kb})$

\section{Abbreviations}

ELISA, enzyme-linked immunosorbent assay; HLA, human leukocyte antigen; $\mathrm{MOI}$, multiplicity of infection; PAMP, pathogen-associated molecular pattern; PC, pilocarpine; qRT-PCR, quantitative real-time PCR; TLR2, toll like receptor 2; TNF, Tumor necrosis factor

\section{Acknowledgements}

We thank Dr. Andrea Bernardino for assistance with ELISAs, Dr. Xavier Alvarez for assistance with microscopic imaging and Dr. Nicholas Crossland (Louisiana State University) for histopathology.

\section{Funding}

This work was supported by Grant P51OD011104/P51RR000164 from the National Center for Research Resources and the Office of Research Infrastructure Programs (ORIP) of the National Institutes of Health.

\section{Availability of data and material}

The raw data from microarrays are available from the Dryad Digital Repository: http://dx.doi.org/10.5061/dryad.s1bg6.

\section{Authors' contributions}

MP, DS and ME conceived and designed the study. MP, DS and ME analyzed the data and drafted the manuscript. DS performed saliva collection, RT-PCR, ELISA, Cytokine array and microarray experiments. ME performed ELISA and tick feeding histology. TM consulted on tick saliva collection and data analysis. JC and DK contributed to microarray analysis. WB performed HPLC analysis. LM assisted with cytokine array experiments and analysis. All authors read, critically revised and approved the final manuscript.

\section{Competing interests}

The authors declare that they have no competing interests.

\section{Consent for publication}

Not applicable.

\section{Ethics approval and consent to participate}

Practices in the housing and care of rabbits and nonhuman primates conformed to the regulations and standards of the PHS Policy on Humane Care and Use of Laboratory Animals, and the Guide for the Care and Use of Laboratory Animals. The Tulane National Primate Research Center is fully accredited by the Association for the Assessment and Accreditation of Laboratory Animal Care-International. The Institutional Animal Care and Use Committee at the Tulane National Primate Research Center approved all animal-related protocols.

\section{Author details}

${ }^{1}$ Divisions of Bacteriology and Parasitology, Tulane National Primate Research Center, Covington, LA, USA. ${ }^{2}$ Center for Vector-Borne Disease, University of Rhode Island, Kingston, RI, USA. ${ }^{3}$ Comparative Pathology, Tulane National Primate Research Center, Covington, Louisiana, USA. ${ }^{4}$ Department of Microbiology and Immunology, Tulane University Medical School, New Orleans, LA, USA. ${ }^{5}$ Present Address: Department of Biology, University of New Mexico, Albuquerque, NM, USA. ${ }^{6}$ Present Address: AbbVie, $1 \mathrm{~N}$ Waukegan Rd, North Chicago, IL, USA.

Received: 23 February 2016 Accepted: 10 June 2016 Published online: 08 July 2016

\section{References}

1. Guerau-de-Arellano M, Huber BT. Chemokines and Toll-like receptors in Lyme disease pathogenesis. Trends Mol Med. 2005;11:114-20.

2. Brossard M, Wikel SK. Tick immunobiology. Parasitol. 2004;129(Suppl):S161-76.

3. Hovius JW, Levi M, Fikrig E. Salivating for knowledge: potential pharmacological agents in tick saliva. PLoS Med. 2008;5:e43. 
4. Marchal C, Schramm F, Kern A, Luft BJ, Yang X, et al. Antialarmin effect of tick saliva during the transmission of Lyme disease. Infection and Immunity. 2011;79:774-85.

5. Nuttall PA, Labuda M. Tick-host interactions: saliva-activated transmission. Parasitol. 2004;129(Suppl):S177-89.

6. Gillespie RD, Mbow ML, Titus RG. The immunomodulatory factors of bloodfeeding arthropod saliva. Parasite Immunol. 2000;22:319-31.

7. Hovius JW. Spitting image: tick saliva assists the causative agent of Lyme disease in evading host skin's innate immune response. J Investig Dermatol. 2009;129:2337-9.

8. Bernard Q, Gallo RL, Jaulhac B, Nakatsuji T, Luft B, et al. Ixodes tick saliva suppresses the keratinocyte cytokine response to TLR2/TLR3 ligands during early exposure to Lyme borreliosis. Exp Dermatol. 2016;25:26-31.

9. Hovius JW, van Dam AP, Fikrig E. Tick-host-pathogen interactions in Lyme borreliosis. Trends Parasitol. 2007:23:434-8.

10. de Taeye SW, Kreuk L, et al. "Complement evasion by Borrelia burgdorferi: it takes three to tango." Trends Parasitol. 2013;29(3):119-128.

11. Kuthejlová M, Kopecký J, Štěpánová G, Macela A. Tick salivary gland extract inhibits killing of Borrelia afzelii spirochetes by mouse macrophages. Infect Immun. 2001;69:575-8.

12. Kopecky J, Kuthejlova M. Suppressive effect of Ixodes ricinus salivary gland extract on mechanisms of natural immunity in vitro. Parasite Immunol. 1998:20:169-74.

13. Sangamnatdej S, Paesen GC, Slovak M, Nuttall PA. A high affinity serotonin- and histamine-binding lipocalin from tick saliva. Insect Mol Biol. 2002;11:79-86.

14. Wang $\mathrm{H}$, Nuttall PA. Immunoglobulin-binding proteins in ticks: new target for vaccine development against a blood-feeding parasite. Cell Mol Life Sci. 1999;56:286-95.

15. Wang H, Nuttall PA. Immunoglobulin-G binding proteins in the ixodid ticks, Rhipicephalus appendiculatus, Amblyomma variegatum and Ixodes hexagonus. Parasitol. 1995:111:161-5.

16. Guo X, Booth CJ, Paley MA, Wang X, DePonte K, et al. Inhibition of neutrophil function by two tick salivary proteins. Infect Immun. 2009;77:2320-9.

17. Schuijt Tim J, Coumou J, Narasimhan S, Dai J, DePonte K, et al. A tick mannose-binding lectin inhibitor interferes with the vertebrate complement cascade to enhance transmission of the Lyme disease agent. Cell Host Microbe. 2011;10:136-46.

18. Wikel S. Ticks and tick-borne pathogens at the cutaneous interface: host defenses, tick countermeasures, and a suitable environment for pathogen establishment. Front Microbiol. 2013;4.

19. Kazimirova M, Stibraniova I. Tick salivary compounds: their role in modulation of host defences and pathogen transmission. Front Cell Infect Microbiol. 2013;3.

20. Kovar L, Kopecky J, Rihova B. Salivary gland extract from Ixodes ricinus tick polarizes the cytokine profile toward Th2 and suppresses proliferation of T lymphocytes in human PBMC culture. J Parasitol. 2001;87:1342-8.

21. Shih CM, Pollack RJ, Telford 3rd SR, Spielman A. Delayed dissemination of Lyme disease spirochetes from the site of deposition in the skin of mice. J Infect Dis. 1992;166:827-31.

22. Shih CM, Spielman A. Accelerated transmission of Lyme disease spirochetes by partially fed vector ticks. J Clin Microbiol. 1993;31:2878-81.

23. Kitchens RL, Munford RS. Enzymatically deacylated lipopolysaccharide (LPS) can antagonize LPS at multiple sites in the LPS recognition pathway. J Biol Chem. 1995;270:9904-10.

24. Mangelsdorf DJ, Koeffler HP, Donaldson CA, Pike JW, Haussler MR. 1,25Dihydroxyvitamin D3-induced differentiation in a human promyelocytic leukemia cell line (HL-60): receptor-mediated maturation to macrophagelike cells. J Cell Biol. 1984;98:391-8.

25. Purser JE, Norris SJ. Correlation between plasmid content and infectivity in Borrelia burgdorferi. Proc Natl Acad Sci USA. 2000;97:13865-70.

26. Francischetti IMB, Mather TN, Ribeiro JMC. Tick saliva is a potent inhibitor of endothelial cell proliferation and angiogenesis. Thromb Haemost. 2005:94:167-74

27. Cavassani KA, Aliberti JC, Dias AR, Silva JS, Ferreira BR. Tick saliva inhibits differentiation, maturation and function of murine bone-marrow-derived dendritic cells. Immunol. 2005;114:235-45.

28. Keira SM, Ferreira LM, Gragnani A, Duarte IS, Santos IAN. Experimenta model for fibroblast culture. Acta Cir Bras. 2004; 19.
29. Valenzuela JG, Charlab R, Mather TN, Ribeiro JMC. Purification, Cloning, and expression of a novel salivary anticomplement protein from the tick, Ixodes scapularis. J Biol Chem. 2000;275:18717-23.

30. Patton TG, Dietrich G, Brandt K, Dolan MC, Piesman J, et al. Saliva, salivary gland, and hemolymph collection from Ixodes scapularis Ticks. J Vis Exp. 2012:(60):e3894.

31. Pfaffl MW, Horgan GW, Dempfle L. Relative expression software tool (REST) for group-wise comparison and statistical analysis of relative expression results in real-time PCR. Nucleic Acids Res. 2002;30:e36.

32. Brossard M, Fivaz V. Ixodes ricinus L.: mast cells, basophils and eosinophils in the sequence of cellular events in the skin of infested or re-infested rabbits. Parasitol. 1982;85:583-92.

33. Robert C, Kupper TS. Inflammatory skin diseases, T cells, and immune surveillance. N Engl J Med. 1999;341:1817-28.

34. Hajnická V, Vančová I, Kocáková P, Slovák M, Gašperík J, et al. Manipulation of host cytokine network by ticks: a potential gateway for pathogen transmission. Parasitol. 2005;130:333-42.

35. Vančová I, Hajnická V, Slovák M, Nuttall PA. Anti-chemokine activities of ixodid ticks depend on tick species, developmental stage, and duration of feeding. Vet Parasitol. 2010;167:274-8.

36. Hainická V, Vančová-Štibrániová I, Slovák M, Kocáková P, Nuttall PA. Ixodid tick salivary gland products target host wound healing growth factors. Int J Parasitol. 2011:41:213-23.

37. Wooten RM, Ma Y, Yoder RA, Brown JP, Weis JH, et al. Toll-like receptor 2 plays a pivotal role in host defense and inflammatory response to Borrelia burgdorferi. Vector Borne Zoonotic Dis. 2002;2:275-8.

38. MacKenzie KF, Clark K, Naqvi S, McGuire VA, Nöehren G, et al. PGE(2) induces macrophage IL-10 production and a regulatory-like phenotype via a protein kinase A-SIK-CRTC3 Pathway. The J Immunol. 2013;190:565-77.

39. Cervantes JL, Dunham-Ems SM, La Vake CJ, Petzke MM, Sahay B, et al. Phagosomal signaling by Borrelia burgdorferi in human monocytes involves Toll-like receptor (TLR) 2 and TLR8 cooperativity and TLR8-mediated induction of IFN- $\beta$. Proc Natl Acad Sci USA. 2011;108:3683-8.

40. Andor P, Istvan N, Lajos K. Innate Immunity in the Skin: How keratinocytes fight against pathogens. Curr Immunol Rev. 2005;1:29-42.

41. Mahanonda R, Sa-Ard-lam N, Montreekachon P, Pimkhaokham A, Yongvanichit $\mathrm{K}$, et al. IL-8 and IDO Expression by human gingival fibroblasts via TLRs. Immunol. 2007:178:1151-7.

42. Filgueira L, Nestle FO, Rittig M, Joller HI, Groscurth P. Human dendritic cells phagocytose and process Borrelia burgdorferi. J Immunol. 1996;157:2998-3005.

43. Mason LMK, Veerman CC, Geijtenbeek TBH, Hovius JWR. Ménage à trois: Borrelia, dendritic cells, and tick saliva interactions. Trends Parasitol. 2014;30:95-103.

44. Slámová M, Skallová A, PÁleníková J, Kopecký J. Effect of tick saliva on immune interactions between Borrelia afzelii and murine dendritic cells. Parasite Immunol. 2011:33:654-60.

45. Hovius JW, de Jong MA, den Dunnen J, Litjens M, Fikrig E, et al. Salp15 binding to DC-SIGN inhibits cytokine expression by impairing both nucleosome remodeling and mRNA stabilization. PLoS Pathog. 2008;4:e31

46. Skallová A, lezzi G, Ampenberger F, Kopf M, Kopecký J. Tick saliva inhibits dendritic cell migration, maturation, and function while promoting development of Th2 responses. J Immunol. 2008;180:6186-92.

47. Sá-Nunes A, Bafica A, Lucas DA, Conrads TP, Veenstra TD, et al. Prostaglandin E2 is a major inhibitor of dendritic cell maturation and function in Ixodes scapularis saliva. J Immunol. 2007;179:1497-505.

48. Marchal CM, Luft BJ, Yang X, Sibilia J, Jaulhac B, et al. Defensin is suppressed by tick salivary gland extract during the in vitro interaction of resident skin cells with Borrelia burgdorferi. J Investig Dermatol. 2009;129:2515-7.

49. Schramm F, Kern A, Barthel C, Nadaud S, Meyer N, et al. Microarray analyses of inflammation response of human dermal fibroblasts to different strains of Borrelia burgdorferi sensu stricto. PLoS ONE. 2012;7:e40046.

50. Kopecky J, Kuthejlova M, Pechova J. Salivary gland extract from Ixodes ricinus ticks inhibits production of interferon-gamma by the upregulation of interleukin-10. Parasite Immunol. 1999;21:351-6.

51. Schoeler GB, Manweiler SA, Bergman DK, Wikel SK. Influence of repeated infestations with pathogen-free Ixodes scapularis (Acari: Ixodidae) on in vitro lymphocyte proliferation responses of $\mathrm{C} 3 \mathrm{H} / \mathrm{HeN}$ mice. J Med Entomol. 2000;37:885-92

52. Giambartolomei GH, Dennis VA, Lasater BL, Murthy PK, Philipp MT. Autocrine and exocrine regulation of interleukin-10 production in THP-1 cells stimulated with Borrelia burgdorferi lipoproteins. Infect Immun. 2002;70:1881-8. 
53. Antonara S, Ristow L, McCarthy J, Coburn J. Effect of Borrelia burgdorferi OspC at the site of inoculation in mouse skin. Infect Immun. 2010;78:4723-33.

54. Dai J, Narasimhan S, Zhang L, Liu L, Wang P, et al. Tick histamine release factor is critical for Ixodes scapularis engorgement and transmission of the Lyme disease agent. PLoS Pathog. 2010;6:e1001205.

55. Lieskovska J, Kopecky J. Effect of tick saliva on signalling pathways activated by TLR-2 ligand and Borrelia afzelii in dendritic cells. Parasite Immunol. 2012;34:421-9.

56. Ebnet K, Brown KD, Siebenlist UK, Simon MM, Shaw S. Borrelia burgdorferi activates nuclear factor-kappa $B$ and is a potent inducer of chemokine and adhesion molecule gene expression in endothelial cells and fibroblasts. J Immunol. 1997;158:3285-92.

57. Croker BA, Mielke LA, Wormald S, Metcalf D, Kiu H, et al. Socs3 maintains the specificity of biological responses to cytokine signals during granulocyte and macrophage differentiation. Exp Hematol. 2008;36:786-98.

58. Kario E, Marmor MD, Adamsky K, Citri A, Amit I, et al. Suppressors of cytokine signaling 4 and 5 regulate epidermal growth factor receptor signaling. J Biol Chem. 2005;280:7038-48.

59. Sanjabi S, Zenewicz LA, Kamanaka M, Flavell RA. Anti-inflammatory and pro-inflammatory roles of TGF- $\beta, \mathrm{IL}-10$, and IL-22 in immunity and autoimmunity. Curr Opin Pharmacol. 2009:9:447-53.

60. Maurer M, von Stebut E. Macrophage inflammatory protein-1. Int J Biochem Cell Biol. 2004;36:1882-6.

61. Kramer C, Nahmias Z, Norman DD, Mulvihill TA, Coons LB, et al. Dermacentor variabilis: Regulation of fibroblast migration by tick salivary gland extract and saliva. Exp Parasitol. 2008;119:391-7.

\section{Submit your next manuscript to BioMed Central and we will help you at every step:}

- We accept pre-submission inquiries

- Our selector tool helps you to find the most relevant journal

- We provide round the clock customer support

- Convenient online submission

- Thorough peer review

- Inclusion in PubMed and all major indexing services

- Maximum visibility for your research

Submit your manuscript at www.biomedcentral.com/submit
Biomed Central 